\title{
IMPLEMENTASI SISTEM INFORMASI KESEHATAN ANAK SEKOLAH DI WILAYAH KOTA TASIKMALAYA TAHUN 2018
}

\author{
Imas Masturoh $^{1^{*}}$, Heri Djamiatul Maulana ${ }^{1}$, Dewi Lena Suryani ${ }^{1}$ \\ Jurusan Rekam Medik dan Informasi Kesehatan, Poltekkes Kemenkes Tasikmalaya \\ *Email: Imas.mth74@gmail.com
}

\begin{abstract}
Recording the development of health is very important for the continuity of individual medical history data and is absolutely needed by everyone to control the degree of pain. This needs to be supported by the availability of patient health data so that services are intact and comprehensive and sustainable at various age levels including school-age children. To optimize health records for school children in the management of health screening data, the implementation of SIKAS applications in schools and health centers was carried out as implementers of the school health management (UKS). The method used was in the form of technical assistance to improve knowledge and skills in the implementation of the School Children Health Information System application to 8 UKS teachers in healthy schools and 8 UKS Puskesmas administrators throughout Tasikmalaya City with the aim of recording first grade students from 8 elementary school healthy schools in cities Tasikmalaya. The results of the activity indicate that the application can be used easily but it requires the readiness of resources that can focus on inputting data. There are still weaknesses in the report on the results of recording the network, which cannot be done online so that the results cannot be immediately known by the stakeholders.
\end{abstract}

Keywords: Health Information System, school children, SIKAS

\begin{abstract}
ABSTRAK
Pencatatan perkembangan kesehatan sangat penting untuk kesinambungan data riwayat medis individu dan mutlak dibutuhkan oleh setiap orang demi mengendalikan derajat kesakitan. Hal tersebut perlu ditunjang dengan ketersediaan data kesehatan pasien agar pelayanan utuh dan menyeluruh serta berkesinambungan pada berbagai tingkatan usia termasuk pada anak usia sekolah. Untuk mengoptimalkan pencatatan kesehatan pada anak sekolah dalam pengelolaan data penjaringan kesehatan maka dilakukan implementasi aplikasi SIKAS di sekolah dan puskesmas sebagai pelaksana pengelola usaha kesehatan sekolah (UKS). Metode yang digunakan berupa pendampingan teknis untuk meningkatkan pengetahuan dan ketrampilan dalam implementasi aplikasi Sistem Informasi Kesehatan Anak Sekolah kepada 8 guru UKS SD sekolah sehat dan 8 pengelola UKS Puskesmas se-Kota Tasikmalaya dengan sasaran pencatatan adalah siswa kelas 1 dari 8 SD percontohan sekolah sehat di kota Tasikmalaya. Hasil kegiatan menunjukkan bahwa aplikasi dapat digunakan dengan mudah namun diperlukan kesiapan sumber daya yang dapat fokus dalam melakukan input data. Masih terdapat kelemahan dalam laporan hasil pencatatan penjaringan yaitu belum dapat dilakukan secara online sehingga hasilnya tidak dapat langsung diketahui oleh pemangku kebijakan.
\end{abstract}

Kata kunci: Sistem Informasi kesehatan, anak sekolah, SIKAS 


\section{PENDAHULUAN}

Pencatatan perkembangan kesehatan sangat penting untuk kesinambungan data riwayat medis individu dan mutlak dibutuhkan oleh setiap orang demi mengendalikan derajat kesakitan melalui pengoptimalan upaya pelayanan kesehatan. Hal tersebut ditunjang dengan ketersediaan data medis pasien agar pelayanan utuh dan menyeluruh pada berbagai tingkatan usia termasuk pada anak usia sekolah.

Anak usia sekolah dikelompokkan berdasarkan batas usia: prasekolah, usia sekolah, remaja, awal usia dewasa. Anak usia sekolah adalah anak yang sedang menekuni proses pendidikan mulai pada tingkat pra sekolah (TK), sekolah dasar hingga sekolah menengah pertama dan menengah atas. Pada tahap ini masalah kesehatan sangat berpengaruh pada kualitas tumbuh kembang anak di kemudian hari pada saat dewasa. Untuk mencegah atau mengurangi potensi komplikasi dan permasalahan kesehatan anak, perlu dilakukan deteksi dini gangguan kesehatan agar tidak berkembang menjadi masalah berat. Deteksi dini bisa dilakukan dengan meningkatkan perhatian yang lebih besar terhadap usia sekolah, sama halnya dengan perhatian ketika anak masih balita. Hal ini dilakukan dengan harapan tercipta anak usia sekolah yang sehat, cerdas dan berprestasi baik.

Menurut Lita Nurlita bahwa Pencatatan kesehatan pribadi pada anak dapat membantu memastikan anak mendapatkan pelayanan preventif secara tepat waktu. Penyimpanan data kesehatan anak dapat meningkatkan ketercapaian suatu program penegahan seperti imunisasi. Orang tua dan penyelenggara pelayanan kesehatan serta sekolah dapat mengetahui tentang riwayat kesehatan anak dan bersama-sama untuk memantau kesehatan anak melalui pencatatan kesehatan pribadi anak sekolah.

Pada tahun 2016 tim pengabdian masyarakat program studi D-3 Pikes telah melaksanakan upaya pembinaan terhadap dokter kecil dan guru UKS SD Negeri Sukasari 3 dan 4 Kecamatan Tawang Tasikmalaya mengenai pencatatan dan pengelolaan riwayat kesehatan anak usia sekolah dengan memberikan KMS manual dan Raport Kesehatan Anak dalam rangka memantau perkembangan kesehatan siswa siswi SD tersebut. Evaluasi kegiatan menunjukkan, instrument manual telah dapat diterima dan dapat dilaksanakan oleh sekolah. Untuk mengoptimalkan fungsi dan tujuan buku raport kesehatanku dalam pengelolaan data, maka tim pengabdian masyarakat program studi D-3 Pikes telah merancang sistem informasi untuk membantu pengelolaan data penjaringan kesehatan agar kesinambungan data dapat terlaksana dengan optimal, yaitu Sistem Informasi Kesehatan Anak Sekolah (SIKAS) yang digunakan untuk membantu pengelolaan data penjaringan kesehatan. Tujuan kegiatan pengabdian masyarakat ini untuk melakukan implementasi aplikasi SIKAS di sekolah dan puskesmas sebagai pelaksana pengelola usaha kesehatan sekolah (UKS).

\section{METODE}

Metode kegiatan ini berupa pendampingan teknis untuk meningkatkan pengetahuan dan ketrampilan dalam implementasi aplikasi Sistem Informasi Kesehatan Anak Sekolah kepada 8 guru UKS SD sekolah sehat dan 8 pengelola UKS Puskesmas se-Kota Tasikmalaya dengan sasaran pencatatan adalah siswa kelas 1 dari 8 SD percontohan sekolah sehat di kota Tasikmalaya. Tahapan kegiatan yang dilakukan yaitu:

1) Membantu pelaksanaan penjaringan kesehatan di 8 sekolah dasar yang dijadikan percontohan sebagai sekolah sehat yaitu: SD N Citapen, SD N Angkasa, SD N Gobras, SD N Babakan Kadu, SD N Sindangpalay 2, SD N Manangga, SD N Cibeureum dan SD N Amanah

2) Mensosialisasikan dan me-refresh kembali tentang penggunaan aplikasi SIKAS 
3) Melakukan penginstallan aplikasi SIKAS di laptop atau komputer sekolah dan pengelola UKS Puskesmas

4) Pendampingan dalam melakukan input data hasil penjaringan kesehatan ke dalam aplikasi SIKAS

5) Evaluasi terhadap pelaksanaan pencatatan secara manual saat penjaringan, input data hasil penjaringan ke aplikasi SIKAS serta penyajian Laporan data hasil input penjaringan kesehatan dari aplikasi SIKAS.

\section{HASIL DAN PEMBAHASAN}

Hasil yang diperoleh dalam kegiatan Pengabdian Masyarakat mengenai Implementasi Sistem Informasi Kesehatan Anak Sekolah adalah sebagai berikut:

1. Implementasi SIKAS dilaksanakan setelah penjaringan kesehatan. Alur penjaringan kesehatan adalah sebagai berikut: Dinas Kesehatan Kota Tasikmalaya menginstruksikan kepada Puskesmas untuk melakukan penjaringan kesehatan, Dinas Kesehatan bekerja sama dengan Dinas Pendidikan yang membawahi Usaha Kesehatan Sekolah (UKS). Puskesmas membuat jadwal penjaringan kesehatan di sekolah di wilayah kerjanya, Puskesmas melakukan penjaringan kesehatan. Puskesmas melakukan pencatatan hasil penjaringan kesehatan. Puskesmas mengirim hasil penjaringan kepada dinas kesehatan Kota Tasikmalaya dan dikirimkan juga kepada sekolah yang bersangkutan. Pada tahap penjaringan kesehatan ini tim pengabdian masyarakat membantu pelaksanaan penjaringan kesehatan yang dilaksanakan oleh petugas puskesmas di sekolah. Tim pengabdian masyarakat dan mahasiswa prodi D-3 Pikes membantu dalam hal pencatatan buku rapor kesehatan dan rekapitulasi hasil penjaringan kesehatan.

2. Penjaringan kesehatan dilakukan dilakukan satu tahun sekali guna mendeteksi secara dini penyakit pada anak sekolah khususnya pada murid baru kelas 1 (satu). Hal tersebut sesuai dengan tujuan dilakukannya penjaringan kesehatan menurut Kementerian Kesehatan Republik Indonesia tahun 2011 dalam petunjuk teknis penjaringan kesehatan di SD yang menyebutkan bahwa kegiatan pelayanan dasar kesehatan yang dilakukan oleh Puskesmas terhadap sekolah di wilayah kerjanya, yang bertujuan untuk meningkatkan derajat kesehatan peserta didik secara optimal.

3. Hasil wawancara dan observasi terhadap petugas puskesmas menunjukkan bahwa selama ini petugas merasa kewalahan dalam melaksanakan kegiatan penjaringan sekaligus pencatatan karena merangkap tugas dengan kegiatan pelayanan di puskesmas. Sebagian besar pengelola UKS di puskesmas adalah perawat gigi dan sebagian lagi berprofesi bidan. Dengan adanya tambahan pencatatan buku rapor kesehatan anak sekolah beban petugas pengelola UKS puskesmas dalam pengadministrasian menjadi bertambah karena belum semua sekolah mendapatkan sosialisasi dan mendapatkan buku rapor kesehatan serta belum semua sekolah membantu pencatatan hasil penjaringan. Tiga dari delapan sekolah dasar yang dilakukan penjaringan, sudah melakukan pencatatan pada buku rapor kesehatan anak sekolah yaitu SD N Angkasa, SD N Cibeureum dan SD Manangga sementara sekolah dasar yang lainnya belum melakukan pencatatan pada buku rapor kesehatan anak sekolah yaitu: SD N Sindang Palay 2, SD N Sukamanah 4, SD N Citapen, SD N Babakan Kadu dan SD N Gobras

4. Tahap selanjutnya adalah pelaksanaan pengabdian masyarakat melalui penginstallan yang dilakukan pada 16 laptop yang terdiri dari: 8 laptop pengelola UKS SD dan 8 laptop pengelola UKS puskesmas. Dalam melakukan penginstallan aplikasi SIKAS tidak mengalami kendala dalam hal sarana prasarana karena setiap sekolah sudah memiliki laptop, namun di beberapa sekolah memiliki kendala dalam hal sumber daya manusia yang terbiasa mengoperasikan laptop/komputer, belum semua guru UKS mampu dan familiar dengan komputer sehingga input data di beberapa sekolah dilakukan oleh operator, padahal operator juga sudah memiliki 
beban yang cukup tinggi dengan berbagai beban administrasi dan keuangan serta mengajar.

5. Setelah aplikasi SIKAS terinstall, selanjutnya melakukan sosialisasi dan me-refresh kembali tentang aplikasi SIKAS melalui penjelasan dan pendampingan input data hasil penjaringan kesehatan kepada guru UKS Sekolah Dasar dan pengelola UKS Puskesmas. Kendala yang muncul masih tetap pada masalah SDM, selain penginputan data hanya tertumpu pada satu orang juga baik pengelola UKS puskesmas maupun guru UKS atau operator memiliki beban kerja yang rangkap, sehingga input data tidak dapat dilakukan dengan cepat dan pada pelaksanaannya untuk tahap awal dibantu oleh mahasiswa prodi D-3 Pikes.

6. Permasalahan lainnya yang ditemukan adalah adanya beberapa formulir pencatatan kesehatan yang berbeda tapi satu tema sama-sama tentang pencatatan kesehatan yang harus diisi dan dilaporkan ke Dinas Kesehatan. Hal ini menjadi tambahan beban tersendiri bagi para petugas. Dengan adanya buku rapor kesehatan anak sekolah sebetulnya sudah cukup memadai dan komprehensif, hanya buku tersebut belum tersosialisasikan ke semua sekolah. Kelemahan laporan hasil pencatatan penjaringan belum dilakukan secara online sehingga hasilnya tidak dapat langsung diketahui oleh pemangku kebijakan yaitu Dinas Kesehatan.

\section{SIMPULAN}

Implementasi SIKAS dilaksanakan setelah penjaringan kesehatan. Penjaringan kesehatan dilakukan dilakukan satu tahun sekali guna mendeteksi secara dini penyakit pada anak sekolah khususnya pada murid baru kelas 1 (satu). Tiap sekolah memiliki jadwal masing-masing sesuai dengan kesepakatan dengan pihak puskesmas. Hasil penjaringan dicatat dan direkap dalam formulir penjaringan yang selanjutnya akan diinput kedalam Aplikasi SIKAS. Aplikasi SIKAS dapat digunakan dengan mudah namun diperlukan kesiapan sumber daya yang dapat fokus dalam melakukan input data. Aplikasi SIKAS ini sendiri masih memiliki kelemahan yaitu belum dilakukan secara online sehingga hasilnya tidak dapat langsung diketahui oleh pemangku kebijakan yaitu Dinas Kesehatan.

\section{DAFTAR PUSTAKA}

1. Nurlita, L. Personal Health Record. http://www.kompasiana.com/litanurlita/sistem-pencatatanelektronik-kesehatan-individu-personal-health-record-dalam-program-imunisasi-pada-anak 54f6d068a33311c65c8b4946. Diakses pada tanggal 18 Juni; 2015.

2. Undang Undang Tentang Pokok Kesehatan No.9 tahun 1960 pasal 3 ayat (1). https://luk.staff.ugm.ac.id/atur/sehat/UU-9-1960PokokKesehatan.pdf Diakses pada tanggal 18 Juni; 2015.

3. Kemenkes RI. Petunjuk Teknis Penjaringan Kesehatan dan Pemeriksaan Berkala Di Satuan Pendidikan Dasar dan Menengah. Jakarta: Dirjen Bina Gizi dan KIA; 2015.

4. Kemenkes RI. Rapor Kesehatanku Buku Informasi Kesehatan Peserta Didik Tingkat SD/MI. Jakarta: Dirjen Bina Gizi dan KIA; 2015. 